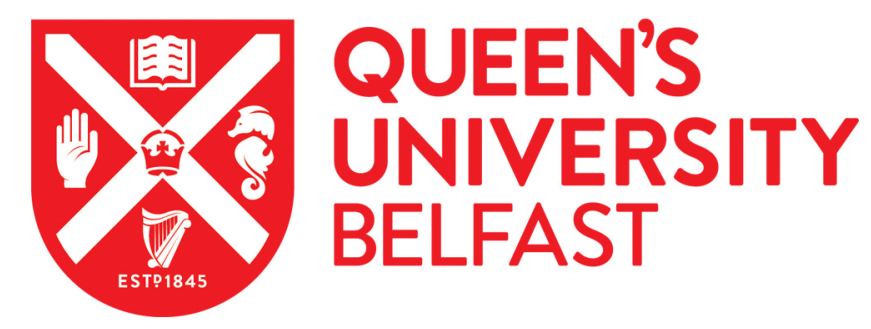

\title{
Atopy, home environment and the risk of childhood-onset type 1 diabetes: a population-based case-control study
}

Cardwell, C., Carson, D., Yarnell, J., Shields, M., \& Patterson, C. (2008). Atopy, home environment and the risk of childhood-onset type 1 diabetes: a population-based case-control study. Pediatric Diabetes, 9(3 PART 1), 191-196. https://doi.org/10.1111/j.1399-5448.2007.00366.x

Published in:

Pediatric Diabetes

Queen's University Belfast - Research Portal:

Link to publication record in Queen's University Belfast Research Portal

\section{General rights}

Copyright for the publications made accessible via the Queen's University Belfast Research Portal is retained by the author(s) and / or other copyright owners and it is a condition of accessing these publications that users recognise and abide by the legal requirements associated with these rights.

Take down policy

The Research Portal is Queen's institutional repository that provides access to Queen's research output. Every effort has been made to ensure that content in the Research Portal does not infringe any person's rights, or applicable UK laws. If you discover content in the Research Portal that you believe breaches copyright or violates any law, please contact openaccess@qub.ac.uk. 


\section{Original Article}

\section{Atopy, home environment and the risk of childhood-onset type 1 diabetes: a population-based case-control study}

\author{
Cardwell CR, Carson DJ, Yarnell J, Shields MD, Patterson CC. Atopy, \\ home environment and the risk of childhood-onset type 1 diabetes: \\ a population-based case-control study. \\ Pediatric Diabetes 2008: 9 (Part I): 191-196. \\ Background: The marked increases in the incidence of type 1 diabetes in \\ recent decades strongly suggest the role of environmental influences. \\ These environmental influences remain largely unknown. \\ Objective: To investigate atopy and home environment (such as children \\ living at home, sharing a bedroom and house moves) as potential risk \\ factors for type 1 diabetes. \\ Subjects and method: In Northern Ireland, 175 children with type 1 \\ diabetes and 4859 control children completed a questionnaire on atopy \\ experience, family composition and home environment. Control children \\ from two age groups (6-8 yr old and 13-14 yr old) were identified from \\ randomly selected primary and secondary schools across Northern \\ Ireland. Cases were identified from a population-based type 1 diabetes \\ register. \\ Results: There was little evidence of a difference in the proportion of \\ participants with a history of atopy in the cases compared with controls. \\ There was a significant reduction in the risk of diabetes in children who \\ lived with more siblings \{odds ratio $(\mathrm{OR})=0.58[95 \%$ confidence interval \\ $(95 \%$ CI $) 0.39-0.85]$ in children who lived with three or more siblings \\ compared with one or none $\}$ and in children who moved house more \\ often [OR $=0.59(95 \%$ CI $0.40-0.88)$ in children who moved house twice \\ or more compared with never]. \\ Conclusion: The reduced risk of type 1 diabetes in children living with \\ siblings, sharing a bedroom and moving house more often could reflect \\ the protection afforded by exposure to infections in early life and \\ consequently may provide support for the hygiene hypothesis.
}

\section{Chris R Cardwell, Dennis J Carson, John Yarnell, Mike D Shields and Chris C Patterson}

Department of Epidemiology and Public Health, School of Medicine and Dentistry, The Queen's University of Belfast, Belfast, UK

\author{
Key words: atopy - epidemiology - \\ infection - type 1 diabetes \\ Corresponding author: \\ Dr Chris R Cardwell \\ Department of Epidemiology and \\ Public Health \\ The Queen's University of Belfast \\ Grosvenor Road \\ Belfast BT12 6BJ \\ UK. \\ Tel: +44 2890632610 ; \\ fax: +44 289023 1907; \\ e-mail: c.cardwell@qub.ac.uk
}

Submitted 7 August 2008. Accepted for publication 20 November 2008
Although type 1 diabetes has an important genetic component (1), marked increases in childhood incidence in recent decades $(2,3)$ strongly suggest the role of environmental influences. However, despite $30 \mathrm{yr}$ of investigation, these environmental influences remain largely unknown.

Type 1 diabetes is considered a disease characterized by abnormal type 1 helper $\mathrm{T}$ lymphocyte activity. In contrast, atopic diseases are considered diseases of excessive type 2 helper $\mathrm{T}$ lymphocyte activity. This difference has prompted some investigators to hypothesize that type 1 diabetes and atopic diseases could be inversely related (4), and much research has been conducted on this topic in recent years (5-8).

Another theory, referred to as the hygiene hypothesis, suggests that reduced or delayed exposure to infection especially at an early age may increase the risk of an abnormal immune response, potentially precipitating the onset of type 1 diabetes (9). In support of this hypothesis, various studies have demonstrated a protective effect of exposure to infections at a young age $(10,11)$ and proxy measures for exposure to infection such as day care attendance $(12,13)$ and later birth order (14-17). 


\section{Cardwell et al.}

This study provided the opportunity to investigate both these hypotheses. The aims of this Northern Ireland population-based case-control study were (i) to investigate the association between type 1 diabetes and atopy and (ii) to investigate the association between type 1 diabetes and factors associated with exposure to infection such as family composition and home environment.

\section{Methods}

The International Study of Asthma and Allergies in Childhood (controls)

The International Study of Asthma and Allergies in Childhood (ISAAC) was established to estimate the prevalence of asthma, rhinitis and eczema at various centres across the globe and to make comparisons within and between centres (18). The initial phase obtained information about atopy experience, family composition and home environment from children in two age groups, 6-8 yr old and 13-14 yr old. Northern Ireland was an ISAAC study centre, and children who participated were the control group for this study.

In the younger age group, 40 schools were randomly selected for inclusion, after stratification by health board, and 36 agreed to participate. The parents of all children in year 2, year 3 and year 4 from these schools were asked to fill in a questionnaire about atopy experience, family composition and home environment. The questionnaire included the questions: 'Has your child ever had wheezing or whistling in the chest?' (yes/no) and 'Has your child ever had asthma?' (yes/no). Similar questions were asked for eczema and rhinitis. In the older age group, 32 schools were randomly selected, after stratification by board and type of school (grammar or secondary), and 25 agreed to participate. In each school, a systematic sample of one in two children was taken from year 9 and year 10 . These children were then requested to complete a similar questionnaire. In both age groups, the weight and height of each child were measured at each school. The data for the older age group were collected between April 1996 and June 1996 and for the younger age group, a year later between April 1997 and June 1997.

\section{Northern Ireland type 1 diabetes register (cases)}

In Northern Ireland, a type 1 diabetes register has prospectively recorded newly diagnosed children below the age of $15 \mathrm{yr}$ since 1989. Details of the register have been published previously (19). Cases were identified from this register to compare with controls. In 1999, children on the register mostly between the ages 6-8 and 13-14 yr were identified for inclusion. The ISAAC study questionnaire was issued to each child aged
13-14 yr and the parents of children aged 6-8 yr during routine diabetes clinic visits. The height and weight of each child were measured by a nurse. A questionnaire was mailed directly to the parents of children who did not attend the clinic appointment. Completed questionnaires from both age groups were received between January 1999 and December 1999.

Ethical approval for the study was obtained from Queen's University of Belfast Research Ethics Committee.

\section{Statistical methods}

Height and weight were used to calculate body mass index (BMI), and to take account of age and sex, all were converted to standard deviation scores (SDSs) using the 1990 British Growth Standard (20). The Classification of Occupations 1980 (21) was used to classify the head of household's occupation into nonmanual occupations (comprising social classes I, II and III non-manual) and manual occupations (comprising social classes III manual, IV and V).

Comparisons of characteristics between case and control participants were conducted using $t$-tests for continuous variables and chi-squared tests for categorical variables. Logistic regression was used to estimate odds ratios (ORs) and 95\% confidence intervals (CIs) and to calculate likelihood ratio statistics to test for differences in ORs between categories of explanatory variables and for trends in ORs across categories. Age group was included in the logistic regression model to adjust for any confounding influence. Interactions with age group were tested to investigate if there was a difference in associations between age groups. All statistical analyses were performed using STATA release 8.0 (Stata Corporation, College Station, TX, USA).

\section{Results}

The controls from the ISAAC study completed and returned 2375 and 2484 questionnaires in the younger and older age groups, respectively, representing an overall approximate response rate of $90 \%$, based upon an estimate of the target population. Subsequently, $76 \%$ $(175 / 229)$ of children identified from the type 1 diabetes register responded, and there was little difference in the response rate between the younger and older age groups ( $78 \%, 76 / 98$, and $76 \%, 99 / 131$, respectively). The average age at diagnosis was 3 (standard deviation $=$ 1.69) $\mathrm{yr}$ in the younger age group and 5 (standard deviation $=3.56) \mathrm{yr}$ in the older age.

\section{Patient characteristics}

A smaller proportion of cases compared with controls were male in the younger age group ( 47 vs. $53 \%$ ), but 
a greater proportion were male in the older age group (64 vs. 53\%). The average age of cases was slightly higher than that of the controls in both the younger (7.7 vs. $7.4 \mathrm{yr}$ ) and older age groups (14.2 vs. $13.9 \mathrm{yr}$ ).

There was a slightly higher average BMI in the cases compared with the controls in both the younger $\left(17.4 \mathrm{vs} .16 .3 \mathrm{~kg} / \mathrm{m}^{2}\right)$ and older age groups (20.8 vs. $20.1 \mathrm{~kg} / \mathrm{m}^{2}$ ). In both age groups combined, the average BMI SDS was also higher in the cases compared with the controls ( 0.6 vs. 0.2$)$.

\section{Atopy}

A summary of the comparison of reported atopy experience is contained in Table 1. There was no evidence of any difference in the experience of wheeze $(\mathrm{p}=0.45)$ or reported asthma $(\mathrm{p}=0.19)$ between the cases and the controls. However, in the older age group, a greater proportion of cases reported asthma than controls ( 27 vs. $18 \% ; p=0.02$ ), and there was evidence of a significant difference in the association between the younger and the older age groups $(\mathrm{p}=0.04$, from a test of the interaction using logistic regression). There was no evidence of any difference in the experience of itchy rash between the cases and the controls $(\mathrm{OR}=0.95$; $p=0.79)$. There was a slight reduction in the prevalence of eczema in the cases compared with the controls, but this association did not attain statistical significance $(\mathrm{OR}=0.71 ; \mathrm{p}=0.10)$. There was no evidence of any difference in the experience of rhinitis between cases and controls. Additional adjustments for slight differences in sex and BMI SDS between the cases and controls made little difference to the estimates presented.

\section{Family and home environment}

A summary of the comparison of family composition and home environment between cases and controls is contained in Table 2.
There was no evidence of any difference in the number of siblings or birth order between the cases and the controls. There was a reduction in the risk of diabetes in children who lived with more siblings ( $\mathrm{p}$ for trend $=0.004)$. Overall, the risk of diabetes in children living with three or more siblings was 0.58 (95\% CI 0.39-0.85) times that of children living alone or with one sibling. Similarly, there was evidence of a reduction in the risk of diabetes in children living in households with more people ( $\mathrm{p}$ for trend $=0.02$ ).

There was no evidence of any association between household crowding (as measured by the number of people per bedroom) and type 1 diabetes $(p=0.70)$. In contrast, analysis of the younger age group showed that children sharing a bedroom had a lower risk of type 1 diabetes than those who did not $(\mathrm{OR}=0.62 ; \mathrm{p}=$ $0.05)$. This association was little altered after adjustment for social class $(\mathrm{OR}=0.55 ; 95 \%$ CI $0.33-0.93$; $\mathrm{p}=0.03$ ).

Finally, there was a reduction in the number of house moves in the cases compared with the controls in both age groups ( $\mathrm{p}$ for trend $=0.009$ ). Overall, the risk of diabetes in children who had moved house twice or more was 0.59 (95\% CI 0.40-0.88) times that of children who had never moved house. This association was little altered after adjustment for age, number of siblings, asthma diagnosis and social class (adjusted $\mathrm{OR}=0.55$; 95\% CI 0.36-0.84; $\mathrm{p}$ for trend < 0.001).

There was no evidence of a difference in the association between family composition and home environment variables and diabetes between the two age groups. Additional adjustments for slight differences in sex and BMI SDS between the cases and the controls made little difference to the estimates presented and therefore have not been shown.

\section{Discussion}

In this study, there was no evidence of any association between type 1 diabetes and history of atopy. There was

Table 1. Reported atopy experience in cases (with type 1 diabetes) and controls by age group and in both age groups combined

\begin{tabular}{|c|c|c|c|c|c|c|}
\hline \multirow[b]{2}{*}{ Atopy experience } & \multicolumn{2}{|c|}{ Younger age group } & \multicolumn{2}{|c|}{ Older age group } & \multicolumn{2}{|l|}{ Overall* } \\
\hline & $\begin{array}{l}\text { Cases \% } \\
(n / N)\end{array}$ & $\begin{array}{l}\text { Controls \% } \\
(\mathrm{n} / \mathrm{N})\end{array}$ & $\begin{array}{l}\text { Cases \% } \\
(n / N)\end{array}$ & $\begin{array}{l}\text { Controls \% } \\
(\mathrm{n} / \mathrm{N})\end{array}$ & $\begin{array}{l}\text { OR } \\
(95 \% \mathrm{Cl})\end{array}$ & $\mathrm{p}$ \\
\hline Wheezed ever & $36(27 / 76)$ & $36(851 / 2355)$ & $40(38 / 96)$ & $44(1086 / 2458)$ & $0.89(0.65,1.22)$ & 0.45 \\
\hline Asthma ever & $19(14 / 74)$ & $22(519 / 2348)$ & $27(26 / 95)$ & $18(428 / 2449)$ & $1.28(0.89,1.84)$ & 0.19 \\
\hline Itchy rash† ever & $20(15 / 76)$ & $19(443 / 2355)$ & $23(22 / 96)$ & $25(619 / 2456)$ & $0.95(0.66,1.38)$ & 0.79 \\
\hline Eczema ever & $20(15 / 75)$ & $24(562 / 2315)$ & $10(10 / 96)$ & $16(371 / 2358)$ & $0.71(0.46,1.09)$ & 0.10 \\
\hline $\begin{array}{l}\text { Runny, blocked } \\
\text { nose/sneezeł ever }\end{array}$ & $24(18 / 76)$ & $25(596 / 2361)$ & $43(41 / 96)$ & $49(1195 / 2451)$ & $0.83(0.60,1.15)$ & 0.26 \\
\hline Hay fever ever & $12(9 / 76)$ & $9(197 / 2321)$ & $30(29 / 96)$ & $27(649 / 2393)$ & $1.23(0.84,1.80)$ & 0.29 \\
\hline
\end{tabular}

${ }^{*}$ Adjusted for age group.

†Specifically an itchy rash that was coming and going for at least 6 months.

fDoes not include cold-related sneezing or runny, blocked nose. 
Table 2. Family composition and home environment of cases (with type 1 diabetes) and controls by age group and in both age groups combined

\begin{tabular}{|c|c|c|c|c|c|c|}
\hline & \multicolumn{2}{|c|}{ Younger age group } & \multicolumn{2}{|c|}{ Older age group } & \multicolumn{2}{|l|}{ Overall* } \\
\hline & Cases \% (n) & Controls \% (n) & Cases \% (n) & Controls \% (n) & OR $(95 \% \mathrm{Cl})$ & $p$ \\
\hline \multicolumn{7}{|l|}{ Siblings } \\
\hline 2 or 1 & $\begin{array}{l}47(36) \\
24(18) \\
29(22)\end{array}$ & $\begin{array}{l}44(1027) \\
30(704)\end{array}$ & $\begin{array}{l}31(30) \\
34(33) \\
36(35)\end{array}$ & $\begin{array}{l}26(650) \\
30(728)\end{array}$ & 1.00 & $0.25 \dagger$ \\
\hline \multicolumn{7}{|l|}{ Birth order } \\
\hline $1^{\text {st }}$ born & $39(29)$ & 39 (896) & $34(32)$ & $32(785)$ & 1.00 & \multirow{3}{*}{$0.72 \dagger$} \\
\hline $2^{\text {nd }}$ born & $32(24)$ & 21 (719) & $28(26)$ & $29(713)$ & $0.96(0.65,1.40)$ & \\
\hline $3^{\text {rd }}$ or later born & $28(21)$ & $31(710)$ & $38(36)$ & 38 (935) & $0.94(0.65,1.35)$ & \\
\hline \multicolumn{7}{|c|}{ Number of siblings at home } \\
\hline 0 or 1 & $54(41)$ & $44(1028)$ & $45(44)$ & 35 (854) & 1.00 & \multirow[t]{3}{*}{$0.004 \dagger$} \\
\hline 2 & $24(18)$ & $31(710)$ & $31(30)$ & $29(699)$ & $0.75(0.52,1.07)$ & \\
\hline 3 or more & $22(17)$ & $25(583)$ & $24(23)$ & 37 (899) & $0.58(0.39,0.85)$ & \\
\hline \multicolumn{7}{|c|}{ Number of people at home } \\
\hline Less than 4 & $12(9)$ & $13(297)$ & $12(12)$ & $10(246)$ & 1.00 & \multirow[t]{4}{*}{$0.02 \dagger$} \\
\hline 4 & $42(32)$ & 35 (828) & $35(34)$ & $26(647)$ & $1.16(0.70,1.92)$ & \\
\hline 5 & $25(19)$ & 30 (695) & $31(30)$ & $28(685)$ & $0.91(0.54,1.53)$ & \\
\hline Greater than 5 & $21(16)$ & $23(530)$ & $23(22)$ & 36 (883) & $0.67(0.39,1.15)$ & \\
\hline \multicolumn{7}{|c|}{ Crowding (people per bedroom) } \\
\hline Less than 1 & $55(41)$ & $51(1184)$ & $67(62)$ & $67(1635)$ & 1.00 & \multirow[t]{2}{*}{0.70} \\
\hline 1 or more & $45(34)$ & 49 (1146) & $33(31)$ & 33 (799) & $0.94(0.68,1.29)$ & \\
\hline \multicolumn{7}{|l|}{ Shares bedroom $\ddagger$} \\
\hline No & $65(48)$ & $53(1250)$ & & & 1.00 & \multirow[t]{2}{*}{0.05} \\
\hline \multirow{2}{*}{\multicolumn{7}{|c|}{ Number of house moves }} \\
\hline & & & & & & \\
\hline Never & $45(34)$ & $42(969)$ & $45(44)$ & $34(826)$ & 1.00 & \multirow[t]{3}{*}{$0.009+$} \\
\hline & $33(25)$ & $34(800)$ & 31 (30) & $29(702)$ & $0.84(0.59,1.20)$ & \\
\hline 2 or more & $21(16)$ & $24(561)$ & $24(23)$ & 37 (894) & $0.59(0.40,0.88)$ & \\
\hline
\end{tabular}

${ }^{\star}$ Adjusted for age group.

†Test for trend across categories.

‡Data not available for younger age group.

a reduction in the risk of diabetes in children who lived with a greater number of siblings and in children who shared a bedroom. There was also a reduction in the risk of diabetes in children who moved house more often.

A strength of this study was that atopy was ascertained using a validated questionnaire $(18,22)$ that included a range of definitions for asthma, eczema and rhinitis including symptoms and diagnosis. Also, high response rates were attained in cases and controls, 76 and $90 \%$, respectively (unusually the controls had a slightly higher response rate than that of the cases possibly because the controls were surveyed at school). However, atopy history was not ascertained prior to diabetes diagnosis. Consequently, atopy may have been more readily recognized after diabetes onset when cases will have greater contact with health services compared with controls. Of less concern, there was a slight delay between control and case data collection (of between 18 and 33 months in the younger age group and between 30 and 45 months in the older age group). There is also a possibility that observed associations with diabetes may have arisen by chance because of the number of exposures investigated and that true associations of weak magnitude were not detected as significant be- cause of a lack of power. Also, as with all observational studies, it is impossible to rule out the effect of confounding by unrecorded variables such as birth weight, parental age and increased growth.

A meta-analysis (23) of previous studies of the association between asthma and diabetes revealed an inverse association with OR 0.82 (95\% CI 0.68-0.99), but this study detected little evidence of any association between asthma and diabetes. The observed inverse association $(\mathrm{OR}=0.71)$ between diabetes and reported eczema is consistent with inverse associations observed in previous large studies (5-8) and summarized in a recent meta-analysis (23). However, a larger study would have been required to detect an association of this magnitude as significant. The observed lack of association between hay fever and type 1 diabetes is consistent with previous studies (23). Overall, this study adds little support for any association between atopy and type 1 diabetes.

The lower risk of diabetes in children sharing a bedroom, observed in this study, was similar to the association noted in a previous UK study (24) and was of similar magnitude to a non-significant association noted in an earlier Canadian study (25). This finding, and the observation that children living with more 
siblings have a reduced risk of diabetes, is consistent with studies that have detected a lower risk of type 1 diabetes in children attending day care $(12,13,26)$ and in children with a higher birth order (14-16). The reduced risk of diabetes in children living with more siblings and sharing a bedroom may reflect an increased exposure to infection in early life in these children. Consequently, these findings may provide support for the hygiene hypothesis, which suggests that the developing immune system requires stimulation by exposure to infections and other immune challenges to achieve a mature and balanced repertoire of responses (9). Alternatively, it is possible that the observed reduction in diabetes in children sharing a bedroom could be a consequence of their diabetes, rather than a predisposing factor, as parents may avoid bedroom sharing so that night-time checks on the their child with diabetes does not wake up other siblings.

This is, to our knowledge, the first study to observe a reduction in the risk of type 1 diabetes in children who have moved house more often. A previous small Hungarian study investigated house moves in the year prior to onset but did not observe a significant association with diabetes risk (27). The association observed in our study was little altered after adjustment for sex, age, social class and number of siblings in the household. It also persisted after adjustment for asthma that could have acted as a confounding factor as there was a slightly increased asthma prevalence in children who had moved house more often, an observation consistent with previously conducted analyses (28-30). The association between house moves and type 1 diabetes is consistent with a small area study that detected lower incidence rates in areas with higher population mixing in northern England (31). That study argued that exposure to a wider range of infections in early life provided further protection against type 1 diabetes, and it is possible to speculate that a similar argument could explain the reduced risk with increased house moves noted here.

In conclusion, there was little evidence of an association between atopy and type 1 diabetes in Northern Ireland. There was evidence that living with a greater number of siblings and moving house more often were associated with a reduced risk of diabetes. These associations could reflect the protection afforded by exposure to infections in early life and consequently may provide support for the hygiene hypothesis.

\section{Acknowledgements}

C. R. C. received a Northern Ireland Department of Education and Learning grant. The ISAAC surveys were conducted by staff from the Department of Epidemiology and Public Health, Queen's University Belfast, and were funded by the Department of Health and Social Services, Northern Ireland. Thanks are also due to diabetes clinic staff in the various hospitals for administering the survey in their patients.

\section{References}

1. FIELD LL. Genetic linkage and association studies of type I diabetes: challenges and rewards. Diabetologia 2002: 45: 21-35.

2. Green A, Patterson CC. Trends in the incidence of childhood-onset diabetes in Europe 1989-1998. Diabetologia 2001: 44 (Suppl. 3): B3-B8.

3. Onkamo P, Vaananen S, Karvonen M, Tuomilehto J. Worldwide increase in incidence of type I diabetes - the analysis of the data on published incidence trends. Diabetologia 1999: 42: 1395-1403.

4. Soltesz G. Diabetes in the young: a paediatric and epidemiological perspective. Diabetologia 2003: 46: 447-454

5. The EUROdiab Substudy 2 Study Group. Decreased prevalence of atopic diseases in children with diabetes. J Pediatrics 2000: 137: 470-474.

6. Olesen AB, Juul S, Birkebaek N, Thestrup-Pedersen $\mathrm{K}$. Association between atopic dermatitis and insulindependent diabetes mellitus: a case-control study. Lancet 2001: 357: 1749-1752.

7. Rosenbauer J, Herzig P, Giani G. Atopic eczema in early childhood could be protective against type 1 diabetes. Diabetologia 2003: 46: 784-788.

8. Stene LC, Joner G. Atopic disorders and risk of childhood-onset type 1 diabetes in individuals. Clin Exp Allergy 2004: 34: 201-206.

9. GALE EA. A missing link in the hygiene hypothesis? Diabetologia 2002: 45: 588-594.

10. Gibbon C, Smith T, Egger P, Betts P, Phillips D. Early infection and subsequent insulin dependent diabetes. Arch Dis Child 1997: 77: 384-385.

11. Pundziute-Lycka A, Urbonaite B, Dahlquist G. Infections and risk of type I (insulin-dependent) diabetes mellitus in Lithuanian children. Diabetologia 2000: 43: 1229-1234.

12. The EURODIAB Substudy 2 Study Group. Infections and vaccinations as risk factors for childhood type I (insulin-dependent) diabetes mellitus: a multicentre case-control investigation. Diabetologia 2000: 43: 47-53.

13. McKinney PA, Okasha M, Parslow RC et al. Early social mixing and childhood type 1 diabetes mellitus: a case-control study in Yorkshire, UK. Diabet Med 2000: 17: 236-242.

14. Patterson CC, Carson DJ, Hadden DR, Waugh NR, Cole SK. A case-control investigation of perinatal risk factors for childhood IDDM in Northern Ireland and Scotland. Diabetes Care 1994: 17: 376-381.

15. Wadsworth EJK, Shield JPH, Hunt LP, Baum JD. A case-control study of environmental factors associated with diabetes in the under 5s. Diabet Med 1997: 14: 390-396.

16. Stene LC, Magnus P, Lie RT, Sovik O, Joner G. Maternal and paternal age at delivery, birth order, and risk of childhood onset type 1 diabetes: population based cohort study. BMJ 2001: 323: 369-371.

17. Cardwell CR, Carson DJ, Patterson CC. Parental age at delivery, birth order, birth weight and gestational age are associated with the risk of childhood type 1 diabetes: a UK regional retrospective cohort study. Diabet Med 2005: 22: 200-206.

18. Asher Mi, Keil U, Anderson HR, Beasley R et al. International Study of Asthma and Allergies in 


\section{Cardwell et al.}

Childhood (ISAAC): rationale and methods. Eur Respir J 1995: 8: 483-491.

19. Patterson CC, Carson DJ, Hadden DR. Epidemiology of childhood IDDM in Northern Ireland 1989-1994: low incidence in areas with highest population density and most household crowding. Northern Ireland Diabetes Study Group. Diabetologia 1996: 39: 1063-1069.

20. Freeman JV, Cole TJ, Chinn S, Jones PR, White EM, PREeCE MA. Cross sectional stature and weight reference curves for the UK. Arch Dis Child 1990: 1995: 17-24.

21. Office of Population Censuses and Surveys. Classification of Occupations 1980. London: Her Majesty's Stationary Office, 1980.

22. Pearce N, Sunyer J, Cheng S et al. Comparison of asthma prevalence in the ISAAC and the ECRHS. ISAAC Steering Committee and the European Community Respiratory Health Survey. International Study of Asthma and Allergies in Childhood. Eur Respir $\mathbf{J}$ 2000: 16: 420-426.

23. Cardwell CR, Shields MD, Carson DJ, Patterson CC. A meta-analysis of the association between childhood type 1 diabetes and atopic disease. Diabetes Care 2003: 26: 2568-2574.

24. Marshall Al, Chetwynd A, Morris JA et al. Type 1 diabetes mellitus in childhood: a matched case control study in Lancashire and Cumbria, UK. Diabet Med 2004: 21: 1035-1040.

25. Siemiatycki J, Colle E, Campbell S, Dewar RA, Belmonte MM. Case-control study of IDDM. Diabetes Care 1989: 12: 209-216.

26. Kaila B, Taback SP. The effect of day care exposure on the risk of developing type 1 diabetes: a metaanalysis of case-control studies. Diabetes Care 2001: 24: 1353-1358.

27. Soltesz G, Jeges S, Dahlquist G et al. Nongenetic risk determinants for type-I (insulin-dependent) diabetes-mellitus in childhood. Acta Paediatr 1994: 83: 730-735.

28. Hughes CH, Baumer JH. Moving house: a risk factor for the development of childhood asthma? BMJ 1995: 311: 1069-1070.

29. Strachan DP, Butland BK, Carey IM, Anderson HR. Moving house unlikely to pose substantial risk of childhood asthma. BMJ 1996: 312: 315.

30. Jones RC, Hughes CR, Wright D, Baumer JH. Early house moves, indoor air, heating methods and asthma. Respir Med 1999: 93: 919-922.

31. Parslow RC, McKinney PA, Law GR, Bodansky HJ. Population mixing and childhood diabetes. Int $\mathbf{J}$ Epidemiol 2001: 30: 533-538. 